\title{
Oral hygiene assessment of children treated under general anesthesia
}

\author{
Radosveta Andreeva \\ Department of pediatric dentistry, Faculty of Dental \\ Medicine, Medical University of Varna;
}

\begin{abstract}
The children treated under general anesthesia are mainly 3 groups: children with early childhood caries (ECC); anxious children and children with special health needs. The study aimed at establishing the oral hygiene level in a group of children treated under general anesthesia. Subject of monitoring are 395 children treated under general anesthesia, divided in 3 groups according to the age: 0-5 years; 512 years; 12-18 years. The assessment of oral hygiene status was done by using the Silness-Loe plaque index (PLI). Results: The difference between the three studied groups was statistically significant. In the first group (under 5 years aged children), the index is the lowest $1.41 \pm 0.76$, while the children in the third group - over 12 years of age are with the highest index $2.47 \pm 0.69$. The $\mathrm{OHI}$ index in the second group is $2.01 \pm 0.78$. Conclusion: The higher values of Silness-Loe plaque index in the three groups studied is due to the fact that children treated under general anesthesia are problematic as behavior and physical or mental health, which leads to neglecting of their oral hygiene. With increasing the age, it strengthens its influence one of the most important factors for the occurrence of the carious process - hygiene.
\end{abstract}

Keywords: general anesthesia, oral hygiene, pediatric dentistry. 


\section{Introduction}

Behavioral management has an important role in pediatric dentistry. A large number of children receive dental treatment using behavioral management techniques in dental clinics, with or without local anesthesia (1).

However, there are some cases when children do not receive routine dental treatment and the use of general anesthesia (GA) becomes the only alternative to providing dental care for children in a safe and effective way.

Dental treatment in childhood, accompanied by pain or unpleasant mental or violent experiences, can lead to fear, anxiety and avoidance of treatment even in adulthood. This leads to the search for new options for behavioral and pain control in dental treatment in childhood. The treatment of children under the condition of physical constraint is unacceptable, especially if it is possible to avoid it, by using general anesthesia $(1,2,3)$. A great number of children treated under general anesthesia are with mental or physical disorders (children with special health needs). They have significant prevalence of caries lesions and poor oral hygiene, because of their main diseases. Many of them are using sugar containing medicines, special diet and difficult dental care access $(3,4)$.

\section{Aim}

The aim of this study is to establish the oral hygiene level in a group of children treated under general anesthesia.

\section{Materials and methods}

Subject of monitoring are 395 children treated under general anesthesia, divided in 3 groups according to the age: 0-5 years; $5-12$ years; $12-18$ years. The assessment of oral hygiene status was done by using the Silness -Loe plaque index. The probe is used to assess the amount of dental plaque by sliding over the surfaces of each tooth. The findings are recorded in 4 points: 0 - no plaque; 1 - plaque is located on the cervical area; 2-plaque is visible on the cervical area and interdentally; 3 - plaque covers the entire surface of the tooth. The plaque index is calculating by the adding the scores and dividing them by the number of the teeth assessed. The index is scored in the following way:0- excellent oral hygiene; 1 from0,1 to 0,9- good oral hygiene; 2- from 1,0 to 1,9- satisfactory oral hygiene; 3 - from 2,0 to 3,0 - poor oral hygiene (5). The oral hygiene is assessed plaque index of Silness-Loe and after the involvement of the children under general anesthesia, because of the lack of cooperation with most of the children, treated by this method (6).

\section{Results and Discussion}

The difference between the three studied groups was statistically significant- $X 2=13,8 ; d f=2 ; P=0.0149$ (Table1) 
Table 1. Average values of PLI index in three groups of studied children

\begin{tabular}{|c|c|c|c|c|}
\hline PLI group & $0-5$ years & 5-12 years & 12-18 years & P-value \\
\hline Mean & 1,41 & 2,01 & 2,47 & \multirow{2}{*}{$\begin{array}{c}\mathbf{X}^{2}=13,8 \\
\mathbf{d f}=2 \\
\mathbf{P}=0.0149\end{array}$} \\
\hline
\end{tabular}

In the first group (under 5 years aged children), the index is the lowest (satisfactory oral hygiene) $1.41 \pm$ 0.76 , while the children in the third group - over 12 years of age are with the highest index (poor oral hygiene) $2.47 \pm 0.69$. The PLI index in the second group is $2.01 \pm 0.78$ (Fig. 1)

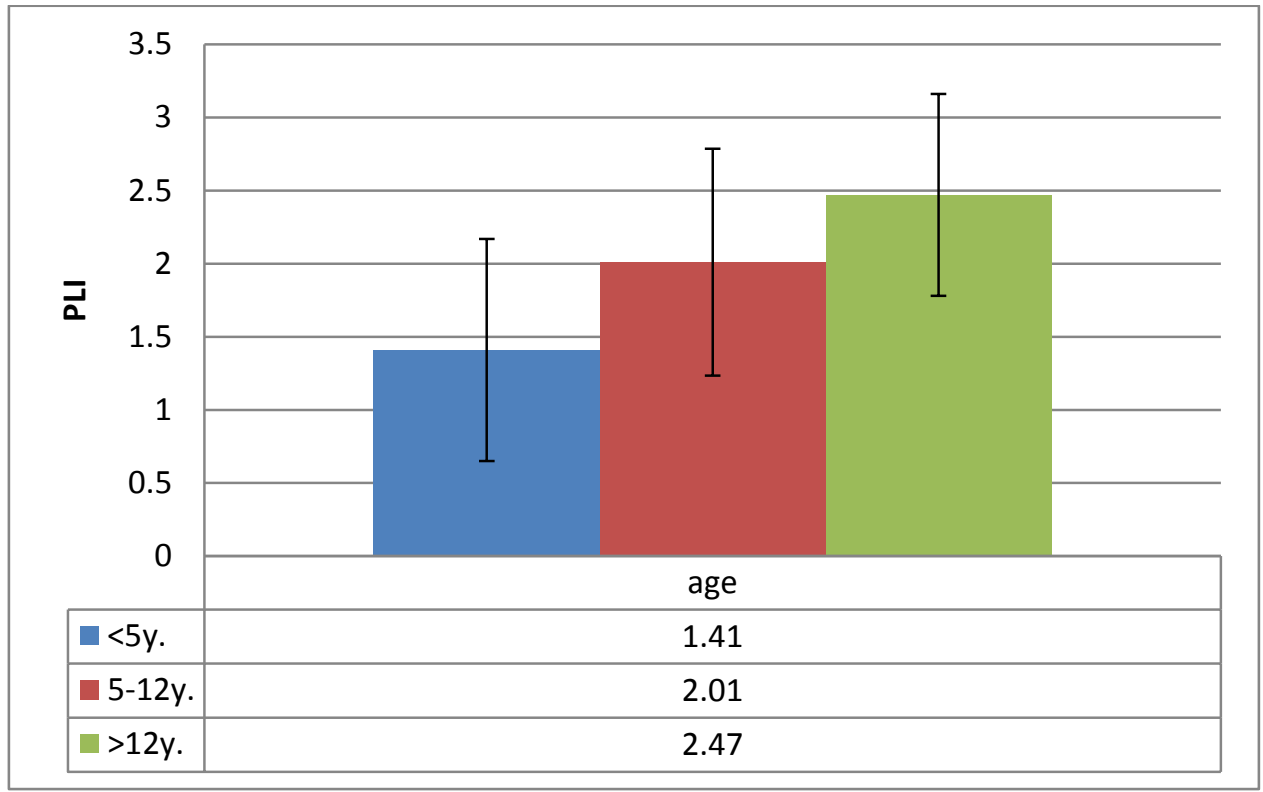

Fig.1. Average values of PLI index according to the age

Most of children have poor or satisfactory oral hygiene. This could be due to the fact that the children from the first studied group are mainly with early childhood caries (ECC) and pain disturbs the proper oral hygiene. Yet their oral hygiene is better than the other two examined groups, perhaps because it is done by parents who are more manual, precise, and strict $(2,5,8)$. The children from the second group have mainly behavioral problems that could concern the oral habits. The high values of the PLI index can be related to the fact that at this age they are washing their teeth themselves. The parents do not always control this process and the children are not yet sufficiently responsible and diligent to do regular and proper oral hygiene procedures $(1,7,9)$. The most of the children with special health needs are disable to 
brush correctly their teeth, because of their physical disability. Parents also often neglect the oral hygiene of these children because they have serious medical problems that are their priority $(10,11)$. The children of all the groups studied have a high carious activity, which shows the relationship between the appearance of carious lesions and oral hygiene, respectively the amount of plaque accumulated (12). Our results correspond with these of some other authors $(5,6,7,8)$, but they differ from the results published by other authors $(9,10,11)$. They assess that the children treated under general anesthesia have good oral hygiene.

\section{Conclusion}

The higher values of Silness-Loe plaque index in the three groups studied is due to the fact that children treated under general anesthesia are problematic as behavior and physical or mental health, which leads to neglecting of their oral hygiene. With increasing the age, it strengthens its influence one of the most important factors for the occurrence of the carious process - hygiene.

\section{References}

1. American Academy of Pediatric Dentistry Clinical Affairs Committee- Behavior Management Subcommitee. Guidelines on behavior quidance for pediatric dental patient. Pediatr Dent 2005;27:92-100

2. Blount RL, Loiselle KA. Behavioural assessment of pediatric pain. Pain Res Manag 2009;14(1):47-52.

3. American Academy of Pediatric Dentistry (AAPD), Clinical Affairs Committee, Council on Clinical AffairsPolicy on medically necessary care, AAPD Reference Manual, 37 (2015), pp. 18-22

4. Wilson S.: Sedation for the Pediatric Patient In Behavior Management in Dentistry for Children, Wiley Blackwell, 2009, p. 131

5. Goodwin M, Pretty IA, Sanders C. A study of the provision of hospital based dental General Anaesthetic services for children in the North West of England: Part 2--the views and experience of families and dentists regarding service needs, treatment and prevention. BMC Oral Health. 2015;15:47.

6. Wong FS, Fearne JM, Brook $\mathrm{AH}$. Planning future general anesthetic services in paediatric dentistry on the basis of evidence: an analysis of children treated in the Day Stay Centre at the Royal Hospitals NHS Trust, London, between 1985-1995. Int Dent J. 1997;47:285-292.

7. Nahid Ramazani, Different Aspects of General Anesthesia in Pediatric Dentistry: A Review, Iran J Pediatr. 2016 Apr; 26(2): e2613

8. DiMaggio Ch., Sun L., Li G.: Early Childhood Exposure to Anesthesia and Risk of Developmental and Behavioral Disorders in a Sibling Birth Cohort. Anesth Analg. 2011;113(5): 1143-1151.

9. Eaton JJ, McTigue DJ, Fields Jr HW, Beck M. Attitudes of contemporary parents toward behavior management techniques used in pediatric dentistry. Pediatr Dent 2005;27:107-113

10. Chhabra N, Chhabra A, Walia G. Prevalence of dental anxiety and fear among five to ten year old children: a behaviour based cross sectional study. Minerva Stomatol. 2012 Mar;61(3):83-910. 
11. Basma K., Fuad H., Dental management for pediatric patients under general anesthesia at Queen Rania hospital for children in Jordan, Journal of royal medical services, vol. 22, p. 78, june 2015

12. Andreeva R, Beltcheva A.,The importance of the OHI- S for children with premature tooth loss. Scripta Scientifica Dentalis, voil.2,No1,2016

\section{Corresponding author:}

Radosveta Andreeva

Department of pediatric dentistry, Faculty of Dental Medicine, Medical University of Varna

email: doctor_ra@abv.bg 